\title{
Internet usage among medical students of Shahid Sadoughi University of Medical Sciences in Yazd in 2020
}

\author{
Jamshid Ayatollahi' ${ }^{1}$, Mahmood Vakili ${ }^{2}$, Sara Tajiki ${ }^{3}$, Mahdie Hamidfar $^{1}$, Seyed Hossein \\ Shahcheraghi ${ }^{*}$
}

1 Infectious Diseases Research Center, Shahid Sadoughi Hospital, Shahid Sadoughi University of Medical Sciences, Yazd, Iran

2 Department of Community Medicine, School of Medicine, Shahid Sadoughi University of Medical Sciences, Yazd, Iran

3 Medical Student, Shahid Sadoughi University of Medical Sciences, Yazd, Iran

*Corresponding Author: Seyed Hossein Shahcheraghi, Infectious Diseases Research Center, Shahid Sadoughi Hospital, Shahid

Sadoughi University of Medical Sciences, Yazd, Iran.

Email: shahcheraghih@gmail.com; Tel: 00989132531389

Received: May 03, 2021; Accepted: June 28, 2021

\begin{abstract}
Medical websites can provide an environment for students to study according to their needs by providing information such as treatment and prevention of diseases, laboratory information and radiography. The purpose of current study was the investigation of internet use status in medical students of Shahid Sadoughi University of Medical Sciences in Yazd, Iran in 2020. The current descriptive-analytical study statistical population was all interns and stagers of Yazd University of Medical Sciences who were national and international students. A questionnaire was used to collect data. After all data were collected, the required analyzes were performed by SPSS software version $22.20 .61 \%$ of the respondents were very confident in the results obtained from the Internet, while the confidence level of the majority is moderately downwards, which was including $83.97 \%$ of the respondents. The results showed that there was no significant relationship between sex, age, level of education, place of residence and time of using the internet for medical study. There was a significant difference in the use of the internet to study medicine in English in the college as well as in the use of the internet in Persian there is a significant difference between men and women, different age groups and place of residence. The highest reason for using the internet among students was related to entertainment. Mobile was the most used tool to connect to the internet. The most used site by students for obtaining medical information was Uptodate. Thus, it is essential to increase speed of internet in universities and enhance available information of Uptodate for accessing easier to scientific data.
\end{abstract}

Keywords: Student, Internet, Medical information.

\section{INTRODUCTION}

One of the most significant technological advances is the internet, which offers a wealth of knowledge on diseases, clinical treatments, and drugs types ${ }^{[1-5]}$.

It is essential to not only provide the medical community with appropriate internet skills, but also to make internet access accessible in institutions that provide education and care related to medicine ${ }^{[1,6]}$.

Usage of the internet is an usual work of college students, partly because they have full-grown up with the scientific technologies specially computers ${ }^{[7,8]}$. It has become ingrained in their everyday contact patterns, and it is as usual as the television or telephone. ${ }^{[9,10]}$. Totally, students apply the internet closely as much for communal announcements and connections as they do for their learning ${ }^{[11,12] .}$

It has also been demonstrated that, despite the fact that doctors ask a variety of questions during patient treatment, many of these questions go unresolved because doctors usually only look for answers to one-third of the queries ${ }^{[13,14]}$.

Therefore, the purpose of current study was the investigation of internet use status in medical students of Shahid Sadoughi University of Medical Sciences in Yazd, Iran in 2020.

\section{MATERIALS AND METHODS}

In this descriptive cross-sectional study conducted in 2020, all medical students of Yazd University of Medical Sciences 
entered the study after obtaining consent. In the study questionnaire, students' demographic information, Internet access location, reason for using the Internet and factors preventing the use of the Internet among students were used.

Sampling was by census. Unfortunately, due to the prevalence of corona, it was not possible to access all medical students and only 262 students completed the questionnaire.

All students of Shahid Sadoughi University of Medical Sciences in Yazd who were intern or stager and wanted to fill out a questionnaire were the inclusion criteria and failure to complete the questionnaire was considered as an exclusion criterion. All information of the participants was used confidentially and only for the purposes of the research.

This study that was related to general medical student thesis was presented in the ethics committee of Shahid Sadoughi University of Medical Sciences of Yazd and was approved with the ethics code IR.SSU.MEDICINE.REC.1399.300.

SPSS22 statistical software was used to analyze the collected data. Data were analyzed using statistical-analytical tests including Student's t test and Chi-Square test. Significance level was considered 0.05 .

\section{RESULTS}

In this study, 144 students (54.96\%) were female and 118 (45.04\%) were male. In terms of age group, 158 people $(60.3 \%)$ in the age group of $21-24$ years, 102 people (38.2\%) were in the age of $25-28$ years and 2 patients $(0.8 \%)$ did not specify their age. 131 (50\%) were stager, 129 (49.24\%) were intern and 2 $(0.76 \%)$ did not specify their degree.

143 (54.58\%) were national students, 118 (45.04\%) were international students and $1(0.38 \%)$ did not specify their status.
$63.36 \%$ of the respondents were non-dormitory and the rest lived in dormitory. Most students (211 or $80.53 \%$ ) used the Internet at home.

The majority of respondents (128 students or $48.85 \%$ ) reported an average internet speed.

258 students (98.47\%) had e-mail. The highest reason for using the Internet among students was related to entertainment with 158 students (60.31\%) and chat with 115 (43.89\%), respectively.

Mobile (257 students or $98.09 \%$ ) and laptops (108 or $41.22 \%$ ) were the most used tools to connect to the internet, respectively.

The majority of respondents including 117 students (44.66\%) stated that they only go to the internet when they have a task.

The most used source by medical students to obtain medical information was the internet (193 students (73.66\%)) and in the next stage Textbook (171 (65.27\%)).

The most used sites by students for obtaining medical information were Uptodate (125 (47.71\%) and PubMed (106 $(40.46 \%))$.

The most searched content about medicine on the internet was clinical pictures (152 students or $58.02 \%$ ).

133 students (50.76\%) preferred the internet for medical study in English and 114 students (43.51\%) preferred the internet for medical study in Persian.

There was a significant difference between the use of the internet for medical studies in English and the school of study ( $p$ $=0.001)($ Table 1$)$ :

Table 1: Internet usage for medical study in English

\begin{tabular}{|c|c|c|c|c|c|c|c|c|}
\hline & & $\begin{array}{l}\text { Never } \\
\mathrm{N}(\%) \\
\end{array}$ & $\begin{array}{l}\text { Very rarely } \\
\mathrm{N}(\%)\end{array}$ & $\begin{array}{l}\text { Rarely } \\
\text { N (\%) }\end{array}$ & $\begin{array}{l}\text { Intermediate } \\
\mathbf{N}(\%)\end{array}$ & $\begin{array}{l}\text { High } \\
\mathrm{N}(\%) \\
\end{array}$ & $\begin{array}{l}\text { Very high } \\
\mathrm{N}(\%)\end{array}$ & P-value \\
\hline \multirow[t]{2}{*}{ Gender } & Male & $3(2.5)$ & $1(0.8)$ & $18(15.3)$ & $57(48.3)$ & $20(16.9)$ & $19(16.1)$ & \multirow[t]{2}{*}{0.532} \\
\hline & Female & $1(0.7)$ & $5(3.5)$ & $21(14.6)$ & $76(52.8)$ & $21(14.6)$ & $20(13.9)$ & \\
\hline \multirow[t]{2}{*}{ Age (Year) } & $21-24$ & $1(0.6)$ & $2(1.3)$ & $22(13.9)$ & $80(50.6)$ & $28(17.7)$ & $25(15.8)$ & \multirow[t]{2}{*}{0.334} \\
\hline & $25-28$ & $3(2.9)$ & $4(3.9)$ & $17(16.7)$ & $52(51)$ & $13(12.7)$ & $13(12.7)$ & \\
\hline \multirow[t]{2}{*}{ Educational Level } & Intern & $2(1.6)$ & $4(3.1)$ & $16(12.4)$ & $70(54.3)$ & $18(14.0)$ & $19(14.7)$ & \multirow[t]{2}{*}{0.675} \\
\hline & Stager & $2(1.5)$ & $2(1.5)$ & $23(17.6)$ & $61(46.6)$ & $23(17.6)$ & $20(15.3)$ & \\
\hline \multirow[t]{2}{*}{ School } & National & $2(1.4)$ & $3(2.1)$ & $14(9.8)$ & $66(46.2)$ & $26(18.2)$ & $32(22.4)$ & \multirow[t]{2}{*}{0.001} \\
\hline & International & $2(1.7)$ & $3(2.5)$ & $25(21.2)$ & $66(55.9)$ & $15(12.7)$ & $7(5.9)$ & \\
\hline \multirow[t]{2}{*}{ Place of residence } & Dormitory & $1(1.0)$ & $0(0.0)$ & $14(14.6)$ & $54(56.2)$ & $17(17.7)$ & $10(10.4)$ & \multirow[t]{2}{*}{0.217} \\
\hline & Non-dormitory & $3(1.8)$ & $6(3.6)$ & $25(15.1)$ & $79(47.6)$ & $24(14.5)$ & $29(17.5)$ & \\
\hline
\end{tabular}

There was a significant difference between the use of the Internet for medical studies in Persian based on gender $(p=0.047)$, different age groups $(p=0.004)$ and place of residence $(p=0.039)$ (Table 2$)$ : 
Table 2: The use of the internet for medical studies in Persian

\begin{tabular}{|c|c|c|c|c|c|c|c|c|}
\hline & & $\begin{array}{l}\text { Never } \\
\mathrm{N}(\%) \\
\end{array}$ & $\begin{array}{l}\text { Very rarely } \\
\mathbf{N}(\%)\end{array}$ & $\begin{array}{l}\text { Rarely } \\
\text { N (\%) }\end{array}$ & $\begin{array}{l}\text { Intermediate } \\
\mathbf{N}(\%)\end{array}$ & $\begin{array}{l}\text { High } \\
\text { N (\%) }\end{array}$ & $\begin{array}{l}\text { Very high } \\
\mathrm{N}(\%)\end{array}$ & P-value \\
\hline \multirow[t]{2}{*}{ Gender } & Male & $1(0.8)$ & $4(3.4)$ & $22(18.6)$ & $46(39.0)$ & $31(26.3)$ & $14(11.9)$ & \multirow[t]{2}{*}{0.047} \\
\hline & Female & $0(0.0)$ & $4(2.8)$ & $13(9.1)$ & $68(47.6)$ & $28(19.6)$ & $30(21.0)$ & \\
\hline \multirow[t]{2}{*}{ Age (Year) } & $21-24$ & $1(0.6)$ & $2(1.3)$ & $19(12.1)$ & $83(52.9)$ & $28(17.8)$ & $24(15.3)$ & \multirow[t]{2}{*}{0.004} \\
\hline & $25-28$ & $0(0)$ & $6(5.9)$ & $15(14.7)$ & $31(30.4)$ & $30(29.4)$ & $20(19.6)$ & \\
\hline \multirow[t]{2}{*}{ Educational Level } & Intern & $0(0.0)$ & $4(3.1)$ & $18(14.1)$ & $53(41.4)$ & $36(28.1)$ & $17(13.3)$ & \multirow[t]{2}{*}{0.196} \\
\hline & Stager & $1(0.8)$ & $3(2.3)$ & $17(13.0)$ & $61(46.6)$ & $22(16.8)$ & $27(20.6)$ & \\
\hline \multirow[t]{2}{*}{ School } & National & $1(0.7)$ & $5(3.5)$ & $24(16.8)$ & $56(39.2)$ & $31(21.7)$ & $26(18.2)$ & \multirow[t]{2}{*}{0.369} \\
\hline & International & $0(0.0)$ & $3(2.6)$ & $11(9.4)$ & $57(48.7)$ & $28(23.9)$ & $18(15.4)$ & \\
\hline \multirow[t]{2}{*}{ Place of residence } & Dormitory & $1(1.1)$ & $3(3.2)$ & $12(12.6)$ & $51(53.7)$ & $20(21.1)$ & $8(8.4)$ & \multirow[t]{2}{*}{0.039} \\
\hline & Non-dormitory & $0(0.0)$ & $5(3.0)$ & $23(13.9)$ & $63(38.0)$ & $39(23.5)$ & $36(21.7)$ & \\
\hline
\end{tabular}

\section{DISCUSSION}

In current study, the highest reason for using the internet among students was related to entertainment and chat, respectively. Mobile and laptops were the most used tools to connect to the internet, respectively. The most used sites by students for obtaining medical information were Uptodate and PubMed.

In a study by Unnikrishnan B, et al. the most of students who contributed in the study were in the age range of $19-21$ years. Email was the most common internet tool applied by almost $87 \%$ students [13]. In present study, the rate of use of E-mail was $11 \%$ among students.

Another study displayed that the majority of the students in medical school were below 30 years. Among these students community, google search engine was recognized as the most important search tool [11]. But, in present study Uptodate was the most used site by students.

In one research, the majority of students were aged 18 . Females were $60 \%$ study cases, and the majority of students were interested in the internet towards textbooks ${ }^{[15]}$. In present study, the most used source by medical students to obtain medical information was the internet and in the next stage textbook, thus, these two studies were similar.

\section{CONCLUSION}

Because the most used source by medical students to obtain information was the internet, it is essential to increase speed of internet in universities and enhance available information of Uptodate for accessing easier to scientific data.

\section{Acknowledgement}

The authors acknowledge infectious diseases research center of Yazd, Iran for their aid.

\section{Conflict of Interest}

We declare that we have no conflict of interest.

\section{Financial Support}

None declared.

\section{REFERENCES}

1. Lal P, Malhotra R, Ahuja C, Ingle G. Internet use among medical students and residents of a medical college of North India. Indian J Community Med. 2006; 31(4):293-4.

2. Rouvinen $\mathrm{H}$, Jokiniemi $\mathrm{K}$, Sormunen $\mathrm{M}$, Turunen $\mathrm{H}$. Internet use and health in higher education students: a scoping review. Health Promotion International. 2021.

3. Haroon MZ, Zeb Z, Javed Z, Awan Z, Aftab Z, Talat W. Internet addiction in medical students. J Ayub Med Coll Abbottabad. 2018; 30(4 Suppl 1):S659-S63.

4. Balhara YPS, Mahapatra A, Sharma P, Bhargava R. Problematic internet use among students in South-East Asia: Current state of evidence. Indian J Public Health. 2018; 62(3):197.

5. Zhang MW, Lim RB, Lee C, Ho RC. Prevalence of internet addiction in medical students: a meta-analysis. Acad Psychiatry. 2018; 42(1):88-93.

6. Madhusudan M, Fernandes SD, Thomas T, Unnikrishnan A, Malakkaran SS, Krishnan $\mathrm{AH}$, et al. Internet Addiction and its determinants among the Students of a Medical College in Kerala. Annals of Community Health. 2018; 6(3):8-13.

7. Osei Asibey B, Agyemang S, Boakye Dankwah A. The internet use for health information seeking among Ghanaian university students: a cross-sectional study. International journal of telemedicine and applications. 2017; 2017.

8. Shiferaw KB, Mehari EA, Eshete T. eHealth literacy and internet use among undergraduate nursing students in a resource limited country: A cross-sectional study. Informatics in Medicine Unlocked. 2020; 18:100273.

9. Moreno MA, Eickhoff J, Zhao Q, Suris J-C. College students and problematic internet use: a pilot study assessing self-appraisal and independent behavior change. J Adolesc Health. 2019; 64(1):131-3.

10. Jia J, Tong W, Zhang J, Liu F, Fang X. Trajectory of problematic internet use across the college years: The role of peer internet overuse behavior and peer attitude toward internet overuse. $\mathrm{J}$ Adolesc. 2021; 86:64-76.

11. Aggarwal Sumit S, Ambalkar Deepti D, Kale Kalpana M, AswarNandkeshav R, Bhatule Prakash R. Pattern of Internet Use Among Medical Students; A Cross Sectional Study. Asian Journal of science and technology. 2015; 6(4):1285-8.

12. Anand N, Thomas C, Jain PA, Bhat A, Thomas C, Prathyusha P, et al. Internet use behaviors, internet addiction and psychological distress among medical college students: A multi centre study from South India. Asian J Psychiatr. 2018; 37:71-7. 
13. Unnikrishnan B, Kulshrestha V, Saraf A, Agrahari A, Prakash S, Samantaray L, et al. Pattern of computer and internet use among medical students in Coastal South India. South East Asian Journal of Medical Education. 2008; 2(2):18-25.

14. Abhilash G, Jagadeesh S, Gopal MV, Kumar KS. A crosssectional study of internet addiction among medical students. 2019.

15. Challa N, Madras V. Attitude, awareness and usage skills of computer and internet among medical students. Age. 2014; 18(18):40. 